\title{
THE TREATMENT OF PSYCHOTIC PATIENTS IN INSTITUTIONS IN THE LIGHT OF PSYCHOANALYSIS.
}

\author{
By M. R. BARKAS, LoNdox.
}

IN a recent paper read before the British Psychological Society Dr. Rickman gave a résumé of what has hitherto been published in psychoanalytical literature on the subject of the psychoses, pointing out how greatly this relatively small body of work has added to our understanding of the meaning of the manifestations of these disorders. Towards the end of his paper, which he was unfortunately obliged to curtail, he implied that it might become possible to treat such cases by analysis. It was this remark that suggested to the writer that this might not be the only improvement in therapeutics to which our increasing knowledge might lead, but that other methods of applying our increased understanding to treatment might also be devised.

It is evident that for a considerable time, even were correct analytical treatment in its present form applicable to the psychoses, it would be impossible to provide it for more than a very few of the large number of psychotic patients already existing, and that, for the present, at any rate, analysis is more suitable as a means of prevention than of cure. Many of the insane are absolutely incapable of co-operation in such treatment, many others would be unwilling, and for the remainder who might be accessible it is probable that a considerable modification of technique, such as is used with young children, would be necessary.

For those of us, therefore, who are faced with the immediate problem of dealing with patients suffering from mental disease, it becomes most important to investigate other means of utilising our knowledge and applying it to the treatment of our patients in the institutions where they must necessarily be placed, either for their own safety or for the welfare of the community.

Two paths offer themselves for the exploration of this subject: In the first place, we may examine the existing conditions of treatment in mental hospitals, and try to see from an analytical standpoint what are the factors underlying those methods of treatment which have been found by experience to be of benefit; in the second place, we may start from the knowledge supplied by analysis of other patients, and by the analytical study, as far as it has gone, of psychotic manifestations, 
and see whether this insight gained into the structure, nature, and mechanisms of psychoses will guide us into new paths of treatment.

The psychosis differs essentially from the neurosis in two ways: As regards libido, there has occurred a regression from the realityprinciple to the pleasure-principle, and from the object relationships to autoerotism and to pregenital modes of gratification; as regards the ego, there has occurred a partial or total disintegration of the developed personality, a loss or distortion of the ego-ideal. What we have learnt from analysis of the development of both ego and libido in the normal person enables us to trace the steps of these regressions; but we have not yet learnt how this backward journey can be stopped or reversed. Our greater understanding of the trends underlying character-formation will undoubtedly help us to prevent recurrent attacks by promoting satisfactory sublimations of the trends which the psychosis frees from repressing bonds when these become intolerable.

Let us first examine the existing treatment given in most mental hospitals. That is the outcome of experience and intuition, and it must always be remembered that the proportion of recoveries in mental illness is actually not inconsiderable. If we exclude those types of psychosis which are certainly due to actual organic destruction of the material basis of mind, we find that in the remaining cases there is a very definite spontaneous tendency to recovery. This seems to be due, as far as one can see, to the fact that the attack of insanity in its acute phase is a sort of letting-off steam, an escape of libido from repressions for which it has become too strong, and that when the excess of pressure has been let off there is a natural tendency for the emotional forces to readjust themselves. When this has occurred, with spontaneous recovery, comes the opportunity of the analyst to step in and promote such a further readjustment of stresses that another accumulation does not take place.

How, then, does any treatment in mental hospitals promote such recovery? That it does so can hardly be disputed, for the recovery rate is roughly proportional to the rapidity with which institutional treatment is applied after the onset of the morbid condition. Statistics are, of course, full of fallacies, and many mild cases do recover at home ; but their duration seems generally longer and the recovery less complete than in an institution. What are the advantages afforded by the institution?

In the first place comes the fact of a complete removal from the environment which the patient has proved unable to withstand. This environment consists, firstly, of the persons of the immediate family around whom his emotional life is interwoven; and, secondly, of the stresses laid on him by the demands of society for adaptation. The institution protects him from the active intervention of these, supplies 
him with a simple environment making no emotional and few adaptational demands on him, one in which his abnormal conduct arouses no hostile criticism, but is taken as a matter of course, and where he sees similar abnormalities among his fellows and becomes again one of a group instead of an isolated alien. All these factors produce a decrease of conflict and removal of stress. He is no longer expected to make any volitional effort-and in certain types of case this is a strong argument in favour of certification as contrasted with voluntary treatment, since under the latter condition the persisting conflict between the feeling of duty towards the home and that of guilt for giving in, on the one hand, and the unconscious hostility towards it on the other, militate against cure.

But beyond these superficial advantages the institution makes its appeal to the unconscious; it forms a shelter and refuge, satisfying the unconscious longing for regression to the antenatal state of freedom from stimulus and effort, of complete protection and satisfaction of all needs by some sheltering body. It supplies a strong, kindly but strict authority to which the individual is wholly subordinated, and which represents omnipotence to him; he becomes a child again, to whatever stage he has regressed ; it feeds, cleans, and disciplines him with kindly strictness, and its personnel intuitively treat him as a child, making upon him no greater demands for adaptation than a parent does of its offspring; it supplies maternal nurses and paternal doctors ; it puts him to bed-another symbolical regression to the intrauterine state-and drugs him into the infantile state of sleep where censorship is relaxed and the unconscious set free. It gradually retraces the child's development, trains him gently towards cleanliness and social decency, encourages sublimation of emotions into simple interests and occupations within a group of his equals in development, and so re-educates him through a series of such groups to the restoration of a normal social life.

It has been said that the fundamental difficulty in the treatment of the psychoses lies in the difficulty of establishing a transference relationship; no one who has worked in a mental hospital can uphold this statement. Transference, both positive and negative, occurs violently towards the persons of the environment, and is used intuitively by the staff of any asylum, and patients of all types respond to some extent.

How can psychoanalytic knowledge help us to use all these factors consciously and with a definite aim in view ? This must be answered differently, according to the type of case. Let us first consider the great bulk of the asylum population, the chronically and hopelessly insane whom, whether owing to organic disease or to other as yet unknown causes, we must at present consider incurable. These patients must be regarded as children, permanently fixed in some stage of 
regression. But it matters greatly both to them and to the community which must maintain them whether they remain infantile, requiring constant nursing and attention, or whether they can be brought to some degree of self-sufficiency ; or again, whether they are to be in constant revolt against their environment, or can become co-operative members of a social group within a protected environment. Observation, an understanding of the trends which strive for gratification, and an appropriate handling will make all the difference to such cases. A conscious handling of transference, a partial rebuilding of the ego-ideal and supplying outlets for sublimation to replace direct gratification, are the clues to success in these cases.

For the recoverable cases, on the other hand, the object of treatment is in the first instance to get over in the least possible time, and with the least possible permanent damage, the explosion of affects which has produced the psychosis.

The way in which institutional treatment can influence the course of these will, of course, depend on the type of psychosis involved. Treatment, as far as it is consciously directed at present, aims merely at the protection of the patient from the worst of the results of his morbid state-giving him warmth, protection from injury, food, supervision of excretion, and promotion of sleep - that is, simply correcting, as far as may be, the abnormalities created by the illness ; for the rest, the policy is one of "wait and see," and, painful though it be to our narcissism, we cannot believe that much that we do beyond this has any effect on the course of the malady. Some recover, some do not, and we can neither predict nor cure. Is it possible to alter this state of things, to see why some cases do recover, and add to their number? We think that it may become possible.

Experience has given us a lead, which may be the clue to the rationale of treatment in general. We often find that the chance intervention of some intercurrent physical disease has a beneficial effect on the mental state of our patients, and a similar effect has recently been obtained by artificially producing some such disease, or by inducing a state of lasting sleep for a prolonged period. Apart from the physical cffects of these, which do not concern us at present, their effect on the mental plane may be explained by the fact that such a state of things places the patient back in a state of even greater infantile dependence than his psychosis had reached, and at the same time it thrusts upon his consciousness his own dependence on his environment for the relief of suffering and the satisfaction of bodily needs, and thus fosters the renewed development of the lost libidinous relationship to external objects. It is often found that after some such acute phase a patient, previously wholly self-absorbed and living in a world of phantasy, may become accessible to re-education. 
This, then, seems to be one foundation for treatment : to let the patient regress even further than he has already done, back to the ultimate goal of all regressive yearnings, the antenatal stage; and then to promote his reliving, in the institutional environment, all the successive phases of development which had previously left fixations and failures of adjustment. He forms substitute transference-relationships to new substitute objects, and gradually rebuilds his adjustments to the simplified reality of the institution, with renewal of self-confidence in the ability of the real ego thus developed to meet the demands of the new ego-ideal, and ultimately to adjust these to the more complicated environment of the external world. In this process the staff can help consciously, as they already do unconsciously, to promote the process of development; knowing the trends which sought expression in the psychosis, they can lead these into socially permissible outlets; they can encourage the patient's tendency to identify them with the imagines which formed the ego-ideal, while modifying gradually the excessive strictness or other distortion which had brought about the conflict between the patient's ego and his unconscious. This does occur to some extent spontaneously ; the superintendent is omnipotent almost to the limit of controlling life and death, and definitely in determining the granting of liberty; he may become the stern, unapproachable, strict, yet just father-ideal, on whom love or hatred may be focussed. Various members of the medical staff may represent various split-off portions of this father-imago, enabling repressed effects to be expressed without retaliation. The nursing staff represent mother-imagines in a similar way.

The next problem which presents itself is that of determining how far it is advisable or necessary to allow and even promote the gratification of libidinal trends in infantile and pregenital modes of expression. Up to a point we cannot direct this, but there comes a time when the influence of the environment may encourage either continued gratification or the beginning of renewed repression and sublimation, and this influence may be the factor which decides whether the patient will lapse into the chronic asylum type, remaining permanently a child, or whether his adult personality will be restored. The problem is similar to that of the original childhood development, where we are equally unable to lay down hard and fast rules. Either a premature deprival or an unduly prolonged gratification of each libidinal phase may lead to morbid reactions, and so far intuition is our only guide. But in dealing with the psychotic patient as with the child, we have hitherto been handicapped by our lack of recognition of the emotional factors involved, both in the reacting individual and in those who have charge of him, and there can be no doubt that the conscious appreciation of these emotional factors will help, and, indeed, is already helping, to promote the recovery of our patients.

vol. v. -No. 20. 
One way in which this can affect treatment is by making us consider in this light our whole handling of the patient and its bearing on his unconscious wishes. The patient may have returned to the infantile absence of excretory control ; instead of feeling, let alone showing, indignation and disgust, we now appreciate its meaning, realize its libidinal value (" present" of bodily product as expression of transference, "smearing" as an expression of anal-erotism, refusal to defæcate as expression of defiance, etc.), and behave accordingly, either permitting the gratification without annoyance, or providing sublimations as a substitute and using the transference towards reeducation into social conduct. If he refuses food, we can try to understand the motives, whether they be self-punishment, ideas of unworthiness and guilt, fears of poisoning, and so forth, and adapt our mode of handling to the situation. We must consider, when tube-feeding has to be undertaken, whether the urgency of the need for nourishment justifies such intervention, which gratifies both the repressed oral-erotic wishes and those for self-punishment, and decide whether such gratification may not do more harm than good. It often leads to a lasting abandonment by the patient of any effort to adopt adult modes of feeding. On the other hand, in a patient who struggles, that resistance and the force it provokes may be satisfying masochistic impulses and allaying a sense of guilt, and șo result in an acceptance by a critical ego-ideal of a substitute atonement.

Obstinate constipation, again, is often found in psychotic patients. If we can understand what are its motives our treatment may be modified. We shall avoid giving enemata in patients with repressed or projected fantasies of homosexual or anal assaults, unless we give them with the conscious intention of providing a relatively allowable substitute gratification. Where the motive is defiance, we shall obviously avoid with even more care than usual any sign of annoyance or anxiety, and cultivate a positive transference as an opposing motive, while refraining as far as possible from any hint of domineering authority. Where there is a fear of childbirth and an identification of ' fæces' with 'child,' it may be possible to attack by an indirect method and get a patient who obstinately maintains in spite of all denials and reassurance that she is swollen up, can get no relief, that no fæces pass or that defæcation is agonizing and associated with the fear of death, to discuss her wishes and phantasies of pregnancy and labour, her childish sexual theories, and so, in time, bring about an alteration of the unconscious attitude symbolized in the symptom.

The same sort of thing applies to masturbation; there is still in asylums a strong tendency to reprimand and show moral indignation and disgust, which adds to the patients' fears that their state is hopeless, that they have ruined themselves in body and mind. A more wide- 
spread understanding of the fact that this sense of guilt is really to be ascribed to the unconscious phantasies underlying the practice would lead to a more rational treatment. Not only reassurance is needed, but the staff should also watch for the hints that the psychotic patient so often gives in a far more evident form than the neurotic, as to the nature of the repressed impulses. It should also be remembered that the institutional conditions impose an absence of any normal sexual gratification, and that therefore a certain amount of masturbation in chronic patients is simply a substitute for a normal life, and needs no treatment beyond the provision of the maximum outlet in sublimated activities.

The fact that the institution removes the patient from normal sexual activities may be either a useful or a harmful thing. If insanity is inherited, it must be beneficial for society to have the patients prevented from procreation. But from the standpoint of the patient it may act in two ways : it will probably be helpful if his conflicts outside are concerned with sexual inadequacy, impotence or the fear of it, frigidity, fear of pregnancy, and so forth, whatever be the underlying cause of these. On the other hand, these conditions may promote continuous regression from a once-achieved genital supremacy to the reactivation of all the foregoing stages, with a corresponding regressive loss of object relations and revival of autoerotism and narcissistic self-sufficiency.

For some cases there is a considerable amount of evidence that institutional life does have this effect. The exact factors determining which are these cases would be well worth investigation. Where the promotion of a short spell of intensive regression permits a fresh start and readaptation, the institution undoubtedly helps. But in dementia præcox, for instance, where the regression is already very great and the capacity for adaptation inherently small, there is more likelihood of the patient becoming chronically so insane as to need life-long institutional care in an asylum than if he can be adequately sheltered at home and his few capabilities for libidinal object-relationships encouraged. If voluntary treatment becomes general, it will become an important problem to decide how far it promotes or militates against normal adaptation to allow the patient who seeks a shelter from the world to receive it and abandon effort.

It would be interesting to examine the different types of psychosis and discuss in detail the mechanisms of their production and the possibilities of their treatment in the light of this knowledge, but our knowledge is hardly yet sufficiently developed to allow of any very definite and exact conclusions. It is evident, however, that already psychoanalysis has illuminated this subject to a quite considerable extent, and that in its light we may hope for more rational and appropriate treatment than was hitherto available, with beneficial results both to 
the patients and to the community in the cure of the insane and the prevention of insanity.

Much of the experience utilized in this paper was obtained in the course of work at the Maudsley Hospital, and I beg to thank the Medical Superintendent, Dr. Mapother, for his permission to publish it. For the opinions expressed I alone am responsible. 